\title{
Linkage studies in Mytilus edulis, the mussel
}

\author{
ANDY R. BEAUMONT \\ School of Ocean Sciences, University of Wales, Bangor, Menai Bridge, Gwynedd LL.59 5EY, Wales, U.K.
}

\begin{abstract}
Electrophoretic data at 10 allozyme loci from the offspring of six single pair matings of Mytilus edulis were analysed for linkage. Significant deviations from expected octopine dehydrogenase $(O d h) /$ phosphoglycerate kinase $(P g k)$ and leucine aminopeptidase $(L a p) /$ esterase D $(E s D)$ di-locus genotype frequencies were evident in two families. In the former case, the recombination frequency was 0.463 suggesting epistasis but in the latter case a recombination frequency of 0.022 indicated almost complete linkage between the Lap and $E s D$ loci. Other loci showing significant linkage were $O d h / L a p$ and $O d h / g l u c o s e$ phosphate isomerase (Gpi). Based on these data and other known linked loci in Mytilus a linkage group comprising Lap, EsD, Odh, mannose phosphate isomerase $(\mathrm{Mpi})$ and possibly also $G \mathrm{pi}$ is proposed. It is noted with interest that the closely related taxa $M$. edulis, $M$. galloprovincialis and $M$. trossulus are distinguished by significant allele frequency variations almost exclusively at loci in this linkage group.
\end{abstract}

Keywords: allozymes, epistasis, linkage, Mytilus edulis.

\section{Introduction}

Of all marine invertebrates, the mussels Mytilus have been most extensively used in both field and laboratory-based allozyme genetic studies. These studies, recently reviewed by Gosling (1992a), have covered taxonomy and geographical differentiation (e.g. Skibinski et al., 1983; MacDonald et al., 1991), selection (Hilbish \& Koehn, 1985), heterosis and heterozygote deficiency (e.g. Zouros et al., 1988; Beaumont, 1991) and pollution effects (Hoare et al., 1994). In spite of the wealth of data from the allozyme approach, there are few published data on linkage. In an early study Mitton et al. (1973) tested for epistasis between the leucine aminopeptidase ( $L a p)$ and aminopetidase $(A p)$ loci in Mytilus edulis L. They found significant dependence between these loci but attributed it to epistasis rather than linkage because the magnitude of the dependency varied with age. More recently Hilbish et al. (1994), based on the study of a hybrid population between $M$. edulis and M. galloprovincialis Lmk., suggested that the esterase $\mathrm{D}(E s D)$ and the octopine dehydrogenase $(O d h)$ loci might be linked.

Allozyme data are available from a number of laboratory-reared single-family crosses (Beaumont et al., 1983, 1988, 1989, 1990) and are here tested for linkage.

\section{Materials and methods}

Between 1980 and 1985 six single-pair matings of $M$. edulis were carried out using adults collected from a natural population in the Menai Strait, Wales, U.K. Progeny were reared in the laboratory up to the juvenile stage (shell length $1-2 \mathrm{~cm}$ ) at which time samples of offspring were taken for electrophoresis. No families were directly related to each other except families 5 and 6 which were half-sibs as they shared the same female parent. Rearing methods were similar for all families and are descibed in Beaumont et al. (1983, 1988). In some families, 3-day-old veliger larvae were partitioned into several separate cultures which were reared from then on under different conditions of salinity or temperature (Beaumont et al., 1988, 1989, 1990; Table 1).

Starch gel electrophoresis was carried out on progeny of the six families using the methods of Beaumont et al. $(1983,1988)$ and the following 10 loci were scored in at least one family: Lap (E.C. 3.4.11 = aminopeptidase I, Young et al., 1979), glucose phosphate isomerase (Gpi, E.C. 5.3.1.9), Odh (E.C. 1.5.1.11), phosphoglucomutase (Pgm, E.C. 2.5.7.1), malate dehydrogenase ( $M d h$, E.C. 1.1.1.37), phosphoglycerate kinase ( $P g k$, E.C. 2.7.2.3), $\beta$-N-acetyl glucose aminidase (Hex, E.C. 3.2.1.30), EsD (E.C. 3.1.1.1), 6-phosphogluconate dehydrogenase (Pdg, E.C. 1.1.1.44) and isocitrate dehydrogenase (Idh, E.C. 1.1.1.42). Data from all cultures within a family were combined for analysis irrespective of the environmental regime under which they had been grown.

Two procedures for analysis were followed. Firstly, expected di-locus genotypes were calculated as the product of the observed single locus frequencies. Observed di-locus frequencies were then tested against 
Table 1 Sources of di-locus data from families of M. edulis reared in the laboratory. Column 1 shows the identification number given to each family in this paper; column 4 indicates their identification in previous publications. In some families cultures were grown under differing temperature or salinity regimes

\begin{tabular}{ccccl}
\hline $\begin{array}{c}\text { Family } \\
\text { number }\end{array}$ & $\begin{array}{c}\text { Number of } \\
\text { cultures }\end{array}$ & $\begin{array}{c}\text { Environmental } \\
\text { variation }\end{array}$ & $\begin{array}{c}\text { Previous } \\
\text { number }\end{array}$ & \multicolumn{1}{c}{ Reference } \\
\hline 1 & 4 & Salinity & M1 & Beaumont et al. $(1988)$ \\
2 & 3 & Temperature & M2 & Beaumont et al. $(1989,1990)$ \\
3 & 4 & Temperature & M3 & Beaumont et al. $(1989,1990)$ \\
4 & 1 & - & M4 & Beaumont et al. $(1989,1990)$ \\
5 & 1 & - & II & Beaumont et al. $(1983)$ \\
6 & 1 & - & I & Beaumont et al. $(1983)$ \\
\hline
\end{tabular}

the expected frequencies using the $\chi^{2}$ goodness of fit test. Secondly, the joint segregation test citerion $\chi_{\mathrm{AB}}^{2}$ (Mather, 1951) was used to test each pairwise comparison for departure from expectations due to linkage. For simplicity of notation, alleles at the two loci under test for linkage were redesignated in the classical form of $\mathrm{A}, \mathrm{A}^{1}, \mathrm{~B}$ and $\mathrm{B}^{1}$ and Mather's (1951) formula was used:

$\chi_{\mathrm{AB}}^{2}=\frac{\left(a_{1}-a_{2}-a_{3}+a_{4}\right)^{2}}{N}$

where $a_{1}=$ number of $A A B B$ individuals, $a_{2}=$ number of $A A B B^{1}$ individuals, $a_{3}=$ number of $A A^{1} B B$ individuals, $a_{4}=$ number of $A A^{1} B B^{1}$ individuals, and $N=$ total number of individuals.

The recombination frequency, $r$, was calculated as:

$r=\frac{\left(a_{1}+a_{4}\right)}{N} \quad$ or $\quad \frac{\left(a_{2}+a_{3}\right)}{N}$

depending on whether $\left(a_{2}+a_{3}\right)$ or $\left(a_{1}+a_{4}\right)$, respectively, was the larger class. Because of this procedure recombination frequency ranges between 0.5 (no linkage) and 0.0 (complete linkage).

Tests for linkage were restricted to pairs of loci at which at least one parent was doubly heterozygous (Mather, 1951) and some di-locus comparisons in several of the families were therefore uninformative. Details of the parental genotypes in all families are given in Table 2.

\section{Results}

Twenty-five di-locus combinations were tested overall and for some combinations there are data from more than one family (Table 3). Sample sizes are large in families 1-4 reflecting the fact that progeny from several cultures were scored. Of the $35 \chi^{2}$ goodness of fit tests, three indicated significant differences between expected and observed di-locus genotype frequencies at the 5 per cent level and two at the 0.1 per cent level (Table 3). Following the consideration of type I errors arising from multiple testing of the same hypothesis (Lessios, 1992), adjustment for significance requires Bonferroni treatment of specific di-locus comparisons across families. Thus $P$ for significance in the $L a p /$ Odh comparison would be $0.05 / 2$ and the family 1 result retains significance $\left(\chi_{[3]}^{2}=10.74,0.01<P<0.02\right)$. The two comparisons showing the highest deviations from expected di-locus genotype frequencies are $O d h /$ $P g k$ in family 1 and $L a p / E s D$ in family 5.

Results of the joint segregation test $\left(\chi_{\mathrm{AB}}^{2}\right.$; Mather, 1951) and recombination frequencies are set out in Tables $4-7$. The significant deviation from expectation of the $O d h / P g k$ di-locus genotypes in family 1 does not appear to be due to linkage because the joint segregation test is not significant and the recombination frequency is close to 0.5 . However, there is significant linkage between $L a p$ and $O d h$ and also between Gpi and $O d h$ in family 1 . A second opportunity to test for linkage between Lap and Odh occurs in family 2 where the result, though significant in the single test $(P<0.05)$, loses significance following Bonferroni treatment $\left(\chi_{[1]}^{2}=4.24, P_{\text {(adjusted) }}>0.05\right)$.

There is evidence for almost complete linkage between Lap and EsD (Table 7) and to demonstrate this evidence the numbers of di-locus genotypes observed are provided in Table 8 together with joint segregation data of EsD and $P g m$ from the same family for comparison.

\section{Discussion}

In a similar study using laboratory-reared crosses of the oyster, Crassostrea virginica (Gmelin), in which 11 loci were studied and two linkage groups were detected, Foltz (1986) discusses the problems, when culturing bivalve larvae and juveniles, of preventing 
Table 2 Parental genotypes in six families of $M$. edulis reared in the laboratory. Details of electrophoresis and allele nomenclature are given in Beaumont et al. $(1983,1988,1989,1990)$. Upper genotype in each row is male parent, lower genotype female parent. At some loci (-), parents were either not scored or were both homozygous for the same allele

\begin{tabular}{|c|c|c|c|c|c|c|}
\hline \multirow[b]{2}{*}{ Locus } & \multicolumn{6}{|c|}{ Family } \\
\hline & 1 & 2 & 3 & 4 & 5 & 6 \\
\hline Lap & $\begin{array}{l}94 / 96 \\
92 / 94\end{array}$ & $\begin{array}{l}94 / 96 \\
92 / 94\end{array}$ & $\begin{array}{l}92 / 94 \\
94 / 94\end{array}$ & $\begin{array}{l}90 / 96 \\
92 / 94\end{array}$ & $\begin{array}{l}94 / 98 \\
94 / 96\end{array}$ & - \\
\hline$G p i$ & $\begin{array}{l}3 / 4 \\
4 / 5\end{array}$ & $\begin{array}{l}3 / 5 \\
5 / 5\end{array}$ & $\begin{array}{l}3 / 5 \\
3 / 5\end{array}$ & $\begin{array}{l}3 / 5 \\
4 / 5\end{array}$ & - & $\begin{array}{l}4 / 5 \\
5 / 5\end{array}$ \\
\hline Odh & $\begin{array}{l}100 / 100 \\
80 / 100\end{array}$ & $\begin{array}{c}100 / 100 \\
80 / 100\end{array}$ & - & - & - & - \\
\hline$M d h$ & $\begin{array}{l}1 / 2 \\
1 / 1\end{array}$ & - & - & - & - & - \\
\hline$P g k$ & $\begin{array}{l}139 / 100 \\
118 / 100\end{array}$ & - & - & - & - & - \\
\hline$I d h$ & $\begin{array}{l}1 / 2 \\
1 / 3\end{array}$ & - & - & - & - & - \\
\hline$P g m$ & - & $\begin{array}{c}108 / 108 \\
92 / 108\end{array}$ & $\begin{array}{l}100 / 108 \\
100 / 108\end{array}$ & - & $\begin{array}{l}100 / 92 \\
100 / 80\end{array}$ & $\begin{array}{l}100 / 92 \\
100 / 80\end{array}$ \\
\hline Hex & - & $\begin{array}{l}3 / 4 \\
2 / 3\end{array}$ & $\begin{array}{l}2 / 2 \\
2 / 3\end{array}$ & - & - & - \\
\hline$P g d$ & - & - & - & - & $\begin{array}{l}100 / 107 \\
100 / 100\end{array}$ & - \\
\hline$E s D$ & - & - & - & - & $\begin{array}{l}100 / 100 \\
100 / 121\end{array}$ & $\begin{array}{l}100 / 121 \\
100 / 121\end{array}$ \\
\hline
\end{tabular}

accidental exchange of larvae between cultures and the ingress of wild larvae into juvenile rearing systems. Zouros et al. (1992) also noted these constraints for genetic studies in bivalves. For the data presented here, settled juveniles were grown in sieves in $75 \mu \mathrm{m}$ filtered sea water which excluded foreign larvae and no foreign genotypes were recorded in any family. Furthermore, no unexpected genotypes were detected in any one family that could have been contaminants from another family. Larval mixing between certain of the families was impossible because they were cultured at different times. Moreover, where families were reared contemporaneously, the chances of exchange were reduced to a minimum because rearing containers were sterilized at each water change, were not aerated (this reduces transmission by splashing) and were also covered with lids.

The significant deviation of $O d h / P g k$ di-locus genotypes from expected frequency in family 1 was not due to linkage but presumably reflected epistatic interaction between the two loci similar to that recorded for Lap and $A p$ by Mitton et al. (1973). However, strong linkage is demonstrated between $L a p$ and $E s D$ and weaker linkage between $O d h$ and $L a p$ and also $O d h$ and Gpi. Hilbish et al. (1994) suggest that EsD and $O d h$ are linked and E. Zouros (personal communication) has found an almost complete linkage between $E s D$ and mannose phosphate isomerase ( $M p i$, E.C. 5.3.1.8) in a family of $M$. edulis $\times M$. trossulus (Gould) used to study mtDNA (Zouros et al., 1992). From this it can be suggested that all these loci might be in the same linkage group and that a possible order might be:

$L a p-E s D-M p i-O d h(-G p i)$.

The presence of Gpi within the linkage group is based on apparent linkage to $O d h$ in family 1 but $G p i$ is clearly not linked to Lap (mean recombination frequency across four families $=0.467 \quad$ (s.d. \pm 0.012 ) 
Table 3 Sample sizes and significance of $\chi^{2}$ goodness of fit of observed to expected di-locus genotype frequencies in six families of $M$. edulis reared in the laboratory

\begin{tabular}{|c|c|c|c|c|c|c|}
\hline \multirow{2}{*}{$\begin{array}{c}\text { Di-locus } \\
\text { comparison }\end{array}$} & \multicolumn{6}{|c|}{ Family } \\
\hline & 1 & 2 & 3 & 4 & 5 & 6 \\
\hline$L a p / G p i$ & 441 & 306 & 437 & 211 & - & - \\
\hline$L a p / O d h$ & $439 *$ & 306 & - & - & - & - \\
\hline Lap/Pgm & - & 306 & 438 & - & 30 & - \\
\hline$L a p / M d h$ & 427 & - & - & - & - & - \\
\hline$L a p / P g k$ & 438 & - & - & - & - & - \\
\hline Lap/Hex & - & 290 & - & - & - & - \\
\hline$L a p / E s D$ & - & - & - & - & $89^{* * * *}$ & - \\
\hline Lap/Pgd & - & - & - & - & 98 & - \\
\hline Lap/Idh & 424 & - & - & - & - & - \\
\hline Gpi/Odh & 440 & - & - & - & - & - \\
\hline Gpi/Pgm & - & - & 438 & - & - & 86 \\
\hline Gpi/Mdh & $426 *$ & - & - & - & - & - \\
\hline Gpi/Pgk & 438 & - & - & - & - & - \\
\hline Gpi/Hex & - & - & 430 & - & - & - \\
\hline Gpi/EsD & - & - & - & - & - & 86 \\
\hline Gpi/Idh & 422 & - & - & - & - & - \\
\hline$O d h / P g m$ & - & 306 & - & - & - & - \\
\hline$O d h / P g k$ & $438 * * *$ & - & - & - & - & - \\
\hline Odh/Hex & - & 292 & - & - & - & - \\
\hline$O d h / I d h$ & 423 & - & - & - & - & - \\
\hline Pgm/Hex & - & 291 & 433 & - & - & - \\
\hline$P g m / E s D$ & - & - & - & - & 30 & 86 \\
\hline $\mathrm{Pgm} / \mathrm{Pgd}$ & - & - & - & - & 90 & - \\
\hline$M d h / P g k$ & 423 & - & - & - & - & - \\
\hline$M d h / I d h$ & $409 *$ & - & - & - & - & - \\
\hline$P g k / I d h$ & 421 & - & - & - & - & - \\
\hline
\end{tabular}

$* P<0.05,{ }^{* *} P<0.01,{ }^{* * *} P<0.001$.

(Tables 4-7)) nor to EsD (recombination frequency $=0.476$, Table 8 ). Further data are required to resolve this apparent anomaly. We are also currently lacking information on recombination frequencies for Lap/Mpi, Odh/Mpi and Gpi/Mpi.

The significance of this result becomes clear when it is noted that these five loci, but particularly $E s D, M p i$ and $O d h$, are the most useful diagnostic loci for distinguishing between the closely related mussels, $M$. edulis, $M$. galloprovincialis and $M$. trossulus (MacDonald et al., 1991). Other loci which have limited usefulness for distinguishing between these species are Pgm, Ap and peptidase II (Aap, E.C. 3.4.11) (MacDonald et al., 1991). Data given here would suggest that Pgm is not linked to any of the other loci studied (mean recombination frequency across six loci $=0.452 \pm 0.003$ ) and Mitton et al.'s (1973) study concluded that Lap and $A p$ exhibited epistasis.
Table 4 Test for linkage in progeny from family 1. Joint segregation test $\chi_{A B}^{2}$ (Mather, 1951) below the diagonal, one degree of freedom; recombination frequency above the diagonal. $-=$ no test possible, neither parent doubly heterozygous for these loci. For other details see Table 3

\begin{tabular}{lcccccc}
\hline & Lap & Gpi & Odh & Mdh & Pgk & Idh \\
\hline Lap & & 0.492 & 0.433 & 0.492 & 0.484 & 0.493 \\
Gpi & 0.111 & & 0.427 & 0.458 & 0.457 & - \\
Odh & $10.845^{* *}$ & $9.309^{* *}$ & & - & 0.463 & 0.475 \\
Mdh & 0.115 & 3.042 & - & & 0.482 & 0.491 \\
Pgk & 0.447 & 3.297 & 2.338 & 0.530 & & 0.496 \\
Idh & 0.085 & - & 1.720 & 2.056 & 1.485 & \\
\hline
\end{tabular}

Table 5 Tests for linkage in progeny from family 2 . For details see Table 4

\begin{tabular}{lccccc}
\hline & Lap & Gpi & Odh & Pgm & Hex \\
\hline Lap & & 0.497 & 0.441 & 0.428 & 0.427 \\
Gpi & 0.013 & & - & - & - \\
Odh & $4.235^{*}$ & - & & 0.477 & 0.469 \\
Pgm & $6.327^{*}$ & - & 0.641 & & 0.447 \\
Hex & $6.083^{*}$ & - & 1.109 & 3.300 & \\
\hline
\end{tabular}

Table 6 Tests for linkage in progeny from family 3. For details see Table 4

\begin{tabular}{lcccc}
\hline & Lap & Gpi & Pgm & Hex \\
\hline Lap & & 0.469 & 0.466 & - \\
Gpi & 1.668 & & 0.477 & 0.498 \\
Pgm & 2.050 & 0.917 & & 0.483 \\
Hex & - & 0.009 & 0.519 & \\
\hline
\end{tabular}

Table 7 Tests for linkage in families 4, 5 and 6. Numbers in parentheses indicate from which family each value is derived. For other details see Table 4

\begin{tabular}{lccccc}
\hline & Lap & Gpi & Pgm & EsD & Pgd \\
\hline Lap & & 0.445 & 0.433 & 0.022 & 0.418 \\
Gpi & $2.407(4)$ & & 0.488 & 0.476 & - \\
Pgm & $0.533(5)$ & $0.050(6)$ & & $0.400(5)$ & 0.389 \\
& & & & $0.488(6)$ & \\
EsD & $81.180(5)^{* * *}$ & $0.186(6)$ & $1.200(5)$ & & - \\
& & & $0.291(6)$ & & \\
Pgd & $2.610(5)$ & - & $4.440(5)^{*}$ & - & \\
\hline
\end{tabular}


Table 8 Numbers of $E s D / L a p$ and $E s D / P g m$ di-locus genotypes recorded from family 5 . The notation used for the joint segregation test is given in parentheses; Lap alleles 94 and 98 are pooled as B, Lap 96 is $B^{1}$; similarly, Pgm alleles 100 and 80 are pooled as $B$ and Pgm 92 is $B^{1}$. For parental genotypes see Table 2. Details of alleles at these three loci in this family are given in Beaumont et al. (1983)

\begin{tabular}{lcrcc}
\hline Es $D$ genotype & Lap genotype & Number & Pgm genotype & Number \\
\hline $100 / 100(A A)$ & $94 / 94(B B)$ & 2 & $100 / 100(B B)$ & 7 \\
& $94 / 96\left(B B^{1}\right)$ & 30 & $100 / 92\left(B B^{1}\right)$ & 3 \\
& $94 / 98(B B)$ & 0 & $100 / 80(B B)$ & 5 \\
& $96 / 98\left(B B^{1}\right)$ & 36 & $80 / 92\left(B B^{1}\right)$ & 6 \\
$100 / 121\left(A A^{1}\right)$ & $94 / 94(B B)$ & 7 & $100 / 100(B B)$ & 2 \\
& $94 / 96\left(B B^{1}\right)$ & 0 & $100 / 92\left(B B^{1}\right)$ & 2 \\
& $94 / 98(B B)$ & 14 & $100 / 80(B B)$ & 1 \\
& $96 / 98\left(B B^{1}\right)$ & 0 & $80 / 92\left(B B^{1}\right)$ & 4 \\
\hline
\end{tabular}

The possibility that the differences between the physiology (e.g. Hilbish et al., 1993), biochemistry (de Zwann \& Mathieu, 1992) and morphology (Gosling, $1992 b$ ) of these three mussel species might be the result of changes involving a single linkage group is intriguing and could provide the focus for further study. Several authors have compared chromosome morphology in $M$. edulis and $M$. galloprovincialis but results are equivocal (see Gosling, 1992a). The use of molecular probes for specific loci may enable the unambiguous association of the linkage group to a particular chromosome.

\section{Acknowledgements}

This work was partly funded by a Natural Environment Research Council grant (GR3/5286). I am grateful to C. M. Beveridge, E. A. Barnet, M. D. Budd and B. Roberts for technical support and I thank T. J. Hilbish and E. Zouros for helpful contributions during the preparation of this paper.

\section{References}

BEAUMONT, A. R. 1991. Genetic studies of laboratory reared mussels, Mytilus edulis: heterozygote deficiencies, heterozygosity and growth. Biol. J. Linn. Soc., 44, 273-285.

BEAUMONT, A. R., BEVERIDGE, C. M., BARNET, E. A. AND BUDD, M. D. 1989. Genetic studies of laboratory reared Mytilus edulis. II. Selection at the leucine aminopeptidase (Lap) locus. Heredity, 62, 169-176.

BEAUMONT, A. R., BEVERIDGE, C. M., BARNET, E. A. AND BUDD, M. D. 1990. Genetic studies of laboratory reared Mytilus edulis. III. Scored loci act as markers for genotype specific mortalities which are unrelated to temperature. Mar. Biol., 106, 227-233.
BEAUMONT, A. R., BEVERIDGE, C. M., BARNET, E. A., BUDD, M. D. AND SMYTH-CHAMOSA, M. 1988. Genetic studies of laboratory reared Mytilus edulis. I. Genotype specific selection in relation to salinity. Heredity, 61, 389-400.

BEAUMONT, A. R., BEVERIDGE, C. M. AND BUDD, M. D. 1983. Selection and heterozygosity within single families of the mussel Mytilus edulis L. Mar. Biol. Letts, 4, 151-161.

DE ZWANN, A. AND MATHIEU, M. 1992. Cellular biochemistry and endocrinology. In: Gosling, E. M. (ed.) The Mussel Mytilus: Ecology, Physiology, Genetics and Culture. Developments in Aquaculture and Fisheries, vol. 25, pp. 223-308. Elsevier, Amsterdam.

FOLTZ, D. W. 1986. Segregation and linkage studies of allozyme loci in pair crosses of the oyster Crassostrea virginica. Biochem. Genet., 24, 941-956.

Gosling, E. M. 1992a. Genetics of Mytilus. In: Gosling, E. M. (ed.) The Mussel Mytilus: Ecology, Physiology, Genetics and Culture. Developments in Aquaculture and Fisheries, vol. 25, pp. 309-382. Elsevier, Amsterdam.

GosLING, E. M. 1992b. Systematics and geographic distribution of Mytilus. In: Gosling, E. M. (ed.) The Mussel Mytilus: Ecology, Physiology, Genetics and Culture. Developments in Aquaculture and Fisheries, vol. 25, pp. 1-20. Elsevier, Amsterdam.

HOARE, K., BEAUMONT, A. R. AND DAVENPORT, J. 1994. Effects of copper exposure during early life stages on heterozygosity in laboratory-reared mussel (Mytilus edulis L.) populations. In: Beaumont, A. R. (ed.) Genetics and Evolution of Aquatic Organisms, pp. 459-466. Chapman \& Hall, London.

HILBISH, T. J., BAYNE, B. L. AND DAY, A. 1994. Genetics of physiological differentiation and biogeographic separation in the marine mussel Mytilus. Evolution (in press).

HILBISH, T. J. AND KOEHN, R. K. 1985. Dominance in physiological phenotypes and fitness at an enzyme locus. Science, 229, 52-54.

LEssios, H. A. 1992. Testing electrophoretic data for agreement with Hardy-Weinberg expectation. Mar. Biol., 112, 517-523. 
MACDONALD, J. H., SEeD, R. AND KOEHN, R. K. 1991. Allozymes and morphometric characters of three species of Mytilus in the Northern and Southern Hemispheres. Mar. Biol., 111, 323-333.

MATHER, K. 1951. The Measurement of Linkage in Heredity. Methuen, London.

MITTON, J. B., KOEHN, R. K. AND PROUT, T. 1973. Population genetics of marine pelecypods. III. Epistasis between functionally related isoenzymes of Mytilus edulis. Genetics, 73, 487-496.

SKIBINSKI, D. O. F., BEARDMORE, J. A. AND CROSS, T. F. 1983. Aspects of the population genetics of Mytilus (Mytilidae;
Mollusca) in the British Isles. Biol. J. Linn. Soc., 19, 137-183.

YOUNG, J. P. W., KOEHN, R. K. AND ARNHEIM, N. 1979. Biochemical characterization of 'LAP', a polymorphic aminopeptidase from the blue mussel, Mytilus edulis. Biochem. Genet., 17, 305-323.

ZOUROS, E., FREEMAN, K. R., BALl, A. O. AND POGSON, G. H. 1992.

Direct evidence for extensive paternal mitochondrial DNA inheritance in the marine mussel Mytilus. Nature, 359, 412-414.

ZOUROS, E., ROMERO-DOREY, M. AND MALLET, A. L. 1988. Heterozygosity and growth in marine bivalves: further data and possible explanations. Evolution, 42, 1332-1341. 